\title{
Robustness-related development of MAN's D38 heavy-duty engine
}

Thomas Leitel, Co-Authors: Dr. Ulrich Wiebicke, Ulrich Boehme, Florian Kraft, all MAN Truck \& Bus AG

Zum Zeitpunkt der Drucklegung lagen diese Unterlagen noch nicht vor. Wir bitten um Verständnis. 